\title{
Influence of low pH on the metabolic activity of Lactobacillus buchneri and Lactobacillus parabuchneri strains in Tilsit-type model cheese
}

\author{
Marie-Therese Fröhlich-Wyder ${ }^{1}$ - Walter Bisig ${ }^{1}$. \\ Dominik Guggisberg ${ }^{1}$ - Stefan Irmler ${ }^{1}$. \\ Ernst Jakob ${ }^{1} \cdot$ Daniel Wechsler ${ }^{1}$
}

Received: 27 January 2015 / Revised: 20 April 2015 / Accepted: 18 May 2015 /

Published online: 24 June 2015

(C) INRA and Springer-Verlag France 2015

\begin{abstract}
Round-shaped and uniformly distributed eyes are important quality features for several Swiss semi-hard cheese varieties such as Tilsit. Recently, the growth of histamineproducing strains of Lactobacillus parabuchneri has been associated with cheese defects, such as crack formation and burning taste. In this paper, the influence of $\mathrm{pH}$ on the metabolic activity of added strains of Lactobacillus buchneri and L. parabuchneri, which possess various $\mathrm{CO}_{2}$-producing activities, was studied in Tilsit-type model cheeses. Two different $\mathrm{pH}$ values were obtained by modifying the cheese-making process (curd washing and type of ripening). Lactate, free amino acids, free short-chain fatty acids and 1,2propanediol were determined in the ripened cheeses. In the acidic cheeses (average $\mathrm{pH}=$ 5.40), significantly more 1,2-propanediol was produced, presumably from lactate. Lactobacillus parabuchneri FAM 21731, a histamine-producing strain, produced small amounts of 1,2-propanediol $\left(0.2 \mathrm{mmol} . \mathrm{kg}^{-1}\right)$ and high amounts of histamine (3.3 mmol. $\left.\mathrm{kg}^{-1}\right)$. Ornithine was produced by all the studied strains, with the highest amount of 9.0 mmol. $\mathrm{kg}^{-1}$ produced by L. parabuchneri FAM 21835 in the acidic cheeses. Standard cheese making representing the high $\mathrm{pH}$ group (curd washed and smear ripened, average $\mathrm{pH}=5.70)$, and the addition of a glutamate decarboxylasepositive L. buchneri, resulted in higher amounts of $\gamma$-aminobutyric acid (GABA) (8.1 compared to $3.3 \mathrm{mmol} . \mathrm{kg}^{-1}$ in the control standard cheeses). Irrespective of the strain, the GABA level was much higher in all the acidic cheeses than in the standard cheeses $(14.7$
\end{abstract}

This paper is part of the Special issue dedicated to the 9th International Cheese Symposium held in Cork, Ireland and organized by Teagasc in collaboration with University College Cork and INRA, 12th \& 13th November 2014.

Marie-Therese Fröhlich-Wyder marie-therese.froehlich@agroscope.admin.ch

1 Agroscope, Institute of Food Sciences IFS, CH-3003 Bern, Switzerland 
compared to $4.6 \mathrm{mmol} . \mathrm{kg}^{-1}$, respectively). The study clearly demonstrates the importance of the cheese $\mathrm{pH}$ in the metabolic activity of the added strains during cheese ripening.

Keywords Cheese - Obligately heterofermentative lactobacilli - Adjunct culture · Carbohydrate catabolism

\section{Introduction}

The number, size, roundness and uniform distribution of eyes are important quality features for several Swiss semi-hard cheese varieties, such as Appenzeller and Tilsit. If eye formation is unsatisfactory, the cheese is downgraded. The production of $\mathrm{CO}_{2}$ by non-starter lactic acid bacteria (NSLAB) is an important contributor to eye formation. The NSLAB in cheese mainly consist of mesophilic lactobacilli. Based on their carbohydrate catabolism, they are subdivided into obligate homofermenters, facultative heterofermenters and obligate heterofermenters. Typically, facultatively heterofermentative lactobacilli predominate. Obligately heterofermentative lactobacilli (OHL) may also be present, especially during the later stages of cheese ripening. According to Coton et al. (2008), Lactobacillus brevis, Lactobacillus fermentum and Lactobacillus parabuchneri are the major OHL present in cheese. Park and Oh (2006) isolated various strains of Lactobacillus buchneri, another OHL, from naturally aged cheese.

Lactobacillus parabuchneri and L. buchneri are of interest because they possess various catabolic activities producing $\mathrm{CO}_{2}$. First, hexoses are degraded by the phosphoketolase pathway, yielding lactate, ethanol/acetate and $\mathrm{CO}_{2}$. Second, both species possess the arginine deiminase (ADI, EC 3.5.3.6) pathway by which arginine is converted into ornithine, with the concomitant release of $\mathrm{CO}_{2}$ and ammonia (Manca de Nadra et al. 1988). Histidine decarboxylase (HDC, EC 4.1.1.22) and glutamate decarboxylase (GAD, EC 4.1.1.15) activity was detected in some strains of L. parabuchneri and L. buchneri, respectively (Fröhlich-Wyder et al. 2013; Cho et al. 2007; Sumner et al. 1985). HDC removes the carboxyl group from histidine to yield histamine, and GAD removes the carboxyl group from glutamate to yield $\gamma$ aminobutyric acid (GABA). Finally, both species produce 1,2-propanediol and acetic acid from lactate, which is probably linked to the formation of $\mathrm{CO}_{2}$ (Oude Elferink et al. 2001).

During cheese making, lactose is rapidly metabolised by the starter culture to lactate (McSweeney 2011), so carbohydrate catabolism by OHL does not essentially contribute to $\mathrm{CO}_{2}$ formation in cheese; other substrates must be available. During cheese ripening, free amino acids accumulate due to the proteolysis of caseins. Both lactate and amino acids are potential substrates for gas formation in L. parabuchneri and L. buchneri. In a previous study, when used as adjuncts for cheese making, we observed that both species metabolised arginine to ornithine and produced 1,2-propanediol (FröhlichWyder et al. 2013). Furthermore, HDC-positive L. parabuchneri and GADpositive L. buchneri produced histamine and GABA, respectively, in cheese. That study clearly showed that these $\mathrm{CO}_{2}$-producing pathways from L. parabuchneri and L. buchneri were active in a cheese environment. 
Both the ADI pathway and the formation of 1,2-propanediol were reported to be regulated by environmental factors. Manca de Nadra et al. (1986) demonstrated that arginine stimulated the enzymes of the ADI pathway in L. buchneri NCDO 110. Other studies confirmed that low $\mathrm{pH}$ activated the production of 1,2-propanediol (Oude Elferink et al. 2001) and that the formation of biogenic amines, such as histamine and GABA, depended on external factors, including the $\mathrm{pH}$, salt concentration and temperature (Linares et al. 2011).

In this work, we studied the influence of $\mathrm{pH}$ on gas production by a thermophilic starter culture and an adjunct culture (L. parabuchneri and L. buchneri) in Tilsit-type model cheeses. Furthermore, we investigated the metabolic pathways involved in the formation of $\mathrm{CO}_{2}$ in L. buchneri and L. parabuchneri during cheese ripening.

\section{Materials and methods}

\subsection{Adjunct cultures and physiological testing}

The adjuncts used in this study are listed in Table 1. They were cultured in MRS broth at $30{ }^{\circ} \mathrm{C}$ (de Man et al. 1960). To assess the formation of GABA, the adjunct cultures were grown in MRS medium, supplemented with $1 \%$ monosodium L-glutamate $(\mathrm{pH}$ 6.2). For the assessment of the formation of histamine, the adjunct cultures were grown in MRS broth, supplemented with $0.2 \%$ L-histidine ( $\mathrm{pH}$ 6.2). To detect the formation of ornithine from Larginine, the adjunct cultures were grown in MAM medium ( $\mathrm{pH}$ 5.8). To assess the formation of 1,2-propanediol, the adjunct cultures were cultivated in MRSMOD medium (modified MRS medium, $\mathrm{pH}$ 3.8), as described by Oude Elferink et al. (2001). The formation of GABA, histamine, ornithine and 1,2-propanediol was verified by high-performance thin-layer chromatography on cellulose plates (Merck, Darmstadt, Germany) by comparing their migration distances to those of standard compounds. The methods used have been previously described in detail (Fröhlich-Wyder et al. 2013).

Table 1 Adjunct cultures used in this study and their biochemical characterisation

\begin{tabular}{|c|c|c|c|c|c|c|}
\hline Adjuncts & $\mathrm{D}-\mathrm{Xyl}{ }^{\mathrm{a}}$ & 1,2-PD & HIST & GABA & Orn & Source or reference \\
\hline $\begin{array}{l}\text { L. buchneri } \\
\text { FAM } 22050\end{array}$ & + & + & - & + & + & $\begin{array}{l}\text { Isolated strain from the silage inoculant } \\
\text { Lalsil Fresh LB (Lallemand S. A., } \\
\text { Saint Simon, France) with the active } \\
\text { ingredient L. buchneri NCIMB } 40788\end{array}$ \\
\hline $\begin{array}{l}\text { L. parabuchneri } \\
\text { FAM } 21731\end{array}$ & - & + & + & - & + & $\begin{array}{l}\text { Agroscope culture collection, isolated } \\
\text { from a Swiss Emmental cheese }\end{array}$ \\
\hline $\begin{array}{l}\text { L. parabuchneri } \\
\text { FAM } 21835\end{array}$ & - & + & - & - & + & $\begin{array}{l}\text { Agroscope culture collection, isolated } \\
\text { from a Swiss Tilsit cheese }\end{array}$ \\
\hline
\end{tabular}

1,2-PD 1,2-propanediol, HIST histamine, GABA $\gamma$-aminobutyric acid, Orn ornithine

${ }^{a}$ Production of acid from D-xylose 


\subsection{Cheese making}

To produce different $\mathrm{pH}$ conditions, half the cheeses were produced and ripened according to the standard protocol, including curd washing and smear ripening (standard cheeses). For the other half, the curd washing step was omitted, and the cheeses were ripened in a plastic film (acidic cheeses). The Tilsit-type model cheeses of $30 \mathrm{~cm}$ in diameter were manufactured in a pilot plant of the Agroscope Research Station at Liebefeld, comprising eight vats. Four standard and four acidic cheeses were produced each from $70 \mathrm{~L}$ of the same batch of pasteurised full-fat $\left(37 \mathrm{~g} . \mathrm{kg}^{-1}\right)$ cow's milk. To each vat containing the 70 L of milk, 5 L of water and $0.2 \%$ starter culture MK 401 (Agroscope, Liebefeld, Switzerland) containing various strains of Lactobacillus delbrueckii subsp. lactis, Streptococcus thermophilus and Lactococcus lactis subsp. lactis and $0.01 \%$ adjunct culture (strain L. buchneri FAM 22050, L. parabuchneri FAM 21731 or L. parabuchneri FAM 21835 pre-cultured in MRS medium) were added. The milk was then pre-ripened at $31-32{ }^{\circ} \mathrm{C}$ for $15 \mathrm{~min}$. The standard and acidic control cheeses were made without the addition of any adjunct culture. For coagulation, $10 \mathrm{~mL}$ of rennet (Winkler GR orange, Winkler AG, Konolfingen, Switzerland) was diluted in $1 \mathrm{~L}$ of water and added to the milk, which was then incubated at $32{ }^{\circ} \mathrm{C}$ for $35 \mathrm{~min}$. According to the manufacturer's instructions, one part of rennet Winkler GR orange clots 9000 parts of non-heated full-fat cow's milk ( $\mathrm{pH} 6.65$ at $32{ }^{\circ} \mathrm{C}$ ) within $30 \mathrm{~min}$, which is equivalent to 194 IMCU.mL ${ }^{-1}$. The coagulum was cut into cubes of about $10 \mathrm{~mm}$ using knives with vertical wires. Thereafter, for the standard cheeses, $20 \mathrm{~L}$ of water was added to the curd-whey mixture. This step was omitted in the acidic cheeses. The curd-whey mixture was then cooked at $44{ }^{\circ} \mathrm{C}$ for $20 \mathrm{~min}$, followed by a final stirring $\left(43{ }^{\circ} \mathrm{C}, 20 \mathrm{~min}\right)$. To remove the whey, the curds were transferred into perforated moulds and pressed for $7.5 \mathrm{~h}$. The cheeses were then immersed in brine solution for $16 \mathrm{~h}$ at $11-13{ }^{\circ} \mathrm{C}$. The four standard cheeses were finally smear ripened at $14-15{ }^{\circ} \mathrm{C}$ and $90-96 \%$ relative humidity for 90 days. During the first 10 days of ripening, the cheeses were smeared daily with the brine solution, which had previously been inoculated with a mixture of Brevibacterium linens, Arthrobacter ssp. and Debaryomyces hansenii (OMK 702, Agroscope, Liebefeld, Switzerland). Thereafter, the brine solution was applied twice a week. The four acidic cheeses were wrapped under vacuum $(-980 \mathrm{mbar})$ in a PA/PE 20/70 plastic film $\left(\mathrm{CO}_{2}\right.$ permeability at $23{ }^{\circ} \mathrm{C}$ and $75 \%$ humidity $146 \mathrm{~mL} .\left(\mathrm{m}^{2} \text {.day.bar }\right)^{-1}$; Inauen Maschinen AG, Herisau, Switzerland) and ripened, together with the standard cheeses, at a temperature of $14-15{ }^{\circ} \mathrm{C}$. The experiment was replicated on the second day ( $N=2$ runs), yielding a total of 16 cheeses. The design is shown in Table 2.

\subsection{Cheese sampling}

Cheese samples were taken aseptically from cheeses after 1 and 90 days of ripening with a cheese trier. The rind (thickness, $5 \mathrm{~mm}$ ) was discarded, and the remaining cheese sample was ground and mixed. 
Table 2 Experimental design of the Tilsit-type model cheese production (Standard pH level includes curd washing and smear ripening; acidic $\mathrm{pH}$ level includes no curd washing and film ripening)

\begin{tabular}{lllll}
\hline Cheese no. & Vat & Day & Adjunct & pH level \\
\hline $1+14$ & $1+6$ & $1+2$ & - & Acidic \\
$2+13$ & $2+5$ & $1+2$ & - & Standard \\
$3+16$ & $3+8$ & $1+2$ & L. buchneri FAM 21731 & Acidic \\
$4+15$ & $4+7$ & $1+2$ & L. buchneri FAM 21731 & Standard \\
$5+10$ & $5+2$ & $1+2$ & L. parabuchneri FAM 21835 & Acidic \\
$6+9$ & $6+1$ & $1+2$ & L. parabuchneri FAM 21835 & Standard \\
$7+12$ & $7+4$ & $1+2$ & L. buchneri FAM 22050 & Acidic \\
$8+11$ & $8+3$ & $1+2$ & L. buchneri FAM 22050 & Standard \\
\hline
\end{tabular}

\subsection{Microbiological analyses}

To enumerate OHL, the $\mathrm{OH}$ medium described by Isolini et al. (1990) and the method described by Fröhlich-Wyder et al. (2013) were used.

\subsection{Chemical and biochemical analyses}

The $\mathrm{pH}$ value of the cheeses was determined with a Metrohm $\mathrm{pH}$-metre 605 equipped with a spear-tip pH electrode (Metrohm AG, Herisau, Switzerland). Free amino acids and histamine were determined with a high-performance liquid chromatograph (HPLC). A gas chromatograph was used to analyse the free short-chain fatty acids and the amount of 1,2-propanediol. These methods were described in detail by Fröhlich-Wyder et al. (2013).

L-, D-lactate and citrate were quantified enzymatically according to the instruction protocol on the kit (R-Biopharm, Darmstadt, Germany).

\subsection{Sensory analysis}

The sensory analysis was performed by a panel of seven experts according to the Agroscope standard protocol. The procedure was described by Guggisberg et al. (2013).

\subsection{Statistical analysis}

A factorial design with two factors (adjunct and $\mathrm{pH}$ level; treated as categorical variables) on four levels (one control and three adjuncts from Table 1) and two levels (standard $\mathrm{pH}$ and acidic $\mathrm{pH}$ ) was applied (Table 2). The experiment was replicated on the second day ( $N=2$ runs, treated as random categorical variable). Statistical analysis of the instrumental data was carried out using the method of analysis of variance with the general linear model (GLM). The software used was SYSTAT 13 (Systat Software, Inc., Chicago IL, USA). Significant differences between the various levels within a factor were accepted at $P \leq 0.05$. 
The analysis of covariance was performed with GLM, and the results are given as squared multiple R (coefficient of determination). It explains how well the model fits the data.

\section{Results and discussion}

\subsection{Biochemical properties of the adjunct cultures}

The results of the physiological testing of the three adjunct cultures used in this study are listed in Table 1. All the selected strains showed the capacity to produce 1,2propanediol and ornithine. One of the two strains of L. parabuchneri additionally produced histamine (FAM 21731), whereas the selected strain of L. buchneri (FAM 22050) isolated from Lalsil fresh LB produced GABA.

\section{$3.2 \mathrm{pH}$ values in the cheeses}

As expected, the different cheese-making steps in the group of standard cheeses (curd washing and smear ripening) and group of acidic cheeses (no curd washing and ripening in a plastic film) led to significant differences in the $\mathrm{pH}$ values and lactate content (Table 3). The lack of a curd washing step had a considerable effect on the amount of lactate in the fresh cheese. As the lactose was not diluted, the lactate fermentation was much more intensive. The ripening in the plastic film and, thus, the absence of lactate-degrading surface flora maintained the $\mathrm{pH}$ of the acidic cheeses at a low level during ripening. These cheeses contained about twice as much lactate as that of the standard cheeses at 90 days of ripening. Accordingly, the mean $\mathrm{pH}$ value of the acidic cheeses was significantly lower than that of the standard cheeses throughout the whole ripening period (5.40 and 5.70, respectively, on day 90) (Table 3).

There was a noticeable difference in the lactate content between the acidic cheeses on day 1 and day 90. In contrast to expectations, the acidic cheeses contained more lactate on day 90 than on day 1 . This finding was likely due to the loss of water during the brine salting and ripening (Table 3). Additionally, as the lactose was not diluted in the vat, the LAB of the starter probably could not degrade all the galactose before brining and thus continued to produce lactic acid during the first days of ripening.

\subsection{Fermentation of lactate to 1,2-propanediol}

The amount of 1,2-propanediol measured in the standard cheeses was very low $\left(0.29 \mathrm{mmol} . \mathrm{kg}^{-1}\right)$ and comparable to the concentration previously found in other cheeses made with the same adjuncts (Fröhlich-Wyder et al. 2013). However, in the acidic cheeses, the degradation of lactate to 1,2-propanediol was significantly higher (3.12 mmol. kg $\left.{ }^{-1} ; P \leq 0.001\right)$. Remarkable differences were observed between the three adjuncts (Table 4): Although L. buchneri FAM 22050 and, particularly, L. parabuchneri FAM 21835 produced high amounts of 1,2-propanediol in the acidic cheeses, L. parabuchneri FAM 21731 did not (Fig. 1). Given the low amount of 1,2- 
Table 3 Content of water, lactate, share of L(+)-lactate and $\mathrm{pH}$ value in Tilsit-type model cheeses grouped according to their $\mathrm{pH}$ level

\begin{tabular}{|c|c|c|c|c|c|c|c|c|c|}
\hline \multirow[t]{2}{*}{ Factor $(\mathrm{N}=8)$} & \multirow[t]{2}{*}{ Level } & \multicolumn{4}{|c|}{ Cheeses 1 day } & \multicolumn{4}{|c|}{ Cheeses 90 days } \\
\hline & & 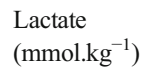 & $\begin{array}{l}\% \mathrm{~L}(+)- \\
\text { lactate }\end{array}$ & $\mathrm{pH}$ & $\begin{array}{l}\text { Water } \\
\left(\mathrm{mg}^{-k^{-1}}\right)\end{array}$ & 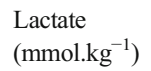 & $\begin{array}{l}\% \mathrm{~L}(+)- \\
\text { lactate }\end{array}$ & $\mathrm{pH}$ & 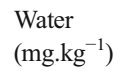 \\
\hline \multirow[t]{2}{*}{ Cheese pH } & Standard ${ }^{\mathrm{a}}$ & 137.2 & 53.4 & 5.08 & 448.3 & 88.0 & 50.4 & 5.70 & 398.8 \\
\hline & Acidic $^{\mathrm{b}}$ & 151.7 & 53.9 & 4.97 & 434.4 & 178.1 & 48.8 & 5.40 & 399.2 \\
\hline \multirow[t]{2}{*}{ GLM ( $P$-value) } & Cheese $\mathrm{pH}$ & $* *$ & n.s. & $* * *$ & $* * *$ & $* * *$ & $* *$ & $* * *$ & n.s. \\
\hline & Day/Run & n.s. & $* *$ & n.s. & $* *$ & n.s. & n.s. & n.s. & $* * *$ \\
\hline
\end{tabular}

n.s. not significant

$* * P \leq 0.01 ; * * * P \leq 0.001$

${ }^{\mathrm{a}}$ Standard $=$ curd washed smear ripened Tilsit-type model cheeses

${ }^{\mathrm{b}}$ Acidic $=$ film ripened Tilsit-type model cheeses produced without curd washing

propanediol produced by L. parabuchneri FAM 21731 and assuming that the fermentation of lactate by L. buchneri and L. parabuchneri to 1,2-propanediol contributed to pH homeostasis, it appears that $L$. parabuchneri FAM 21731 used an alternative pathway to control acidic stress.

Acetic acid is an end product of various fermentative pathways, such as the fermentation of citrate by NSLAB or the fermentation of lactate by propionibacteria or clostridia. Moreover, acetic acid is formed during the degradation of lactate to 1,2-propanediol by L. buchneri or L. parabuchneri. According to Oude Elferink et al. (2001), 1,2-propanediol and acetic acid are produced in equimolar amounts. Figure 2 shows that there was a high correlation in the acidic cheeses between the content of acetic acid and 1,2propanediol $(r=0.994$, with $P<0.001)$. Therefore, most of the acetic acid likely originated from the degradation of lactate by $L$. buchneri or L. parabuchneri. However, it can be concluded from Fig. 2 that approximately $4-5$ mmol of the acetic acid in the acidic cheeses seem to originate from metabolic pathways other than lactate degradation. Based on the analysis of the volatile fatty acids, the fermentation of citrate by NSLAB or lactate by propionibacteria or clostridia was not responsible for the additional acetic acid (data not shown). In the standard cheeses, the correlation between the acetic acid and 1,2-propanediol content was weak but still significant ( $r=0.793$, with $P=0.019$; Fig. 2 ). In these cheeses, up to $14 \mathrm{mmol}$ of the acetic acid could not be attributed to the formation of 1,2-propanediol by NSLAB nor to the metabolic activity of propionibacteria and clostridia (data not shown). Possible explanations for the excess acetic acid could be the degradation of selected amino acids (Yvon et al. 2011; Skeie et al. 2008).

1,2-Propanediol has a slightly sweet taste. The measured amounts of 1,2-propandiol were all well below the taste threshold of $13.9 \mathrm{mmol} . \mathrm{L}^{-1}$, indicated by Hufnagel and Hofmann (2008) for wine. All the same, there was a significant, negative correlation between the sensorial attributes 'bitterness' and 'sweetness' in the model Tilsit-type cheeses $(r=-0.809 ; P<0.001$; Table 5$)$. 
Table 4 Content of lactate, 1,2-propanediol (1,2-PD), acetic acid (C2), soluble nitrogen at pH 4.6 (SN) and non-protein nitrogen (NPN), as well as the $\mathrm{pH}$ value of the Tilsit-type model cheeses produced with various adjuncts after 90 days of ripening. No adjuncts were added to the control cheese

\begin{tabular}{|c|c|c|c|c|c|c|c|}
\hline Factor & Level & $\begin{array}{l}\text { lactate } \\
\left(\mathrm{mmol} \cdot \mathrm{kg}^{-1}\right)\end{array}$ & 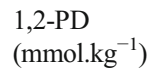 & $\begin{array}{l}\mathrm{C} 2 \\
\left(\mathrm{mmol} . \mathrm{kg}^{-1}\right)\end{array}$ & 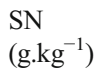 & $\begin{array}{l}\mathrm{NPN} \\
\left(\mathrm{g} . \mathrm{kg}^{-1}\right)\end{array}$ & $\mathrm{pH}$ \\
\hline \multirow[t]{4}{*}{ Adjunct $(\mathrm{N}=4)$} & Control & 139.8 & 0.04 & 5.2 & 9.2 & 6.0 & 5.44 \\
\hline & Lpbu FAM 21731 & 133.4 & 0.22 & 5.5 & 9.7 & 6.1 & 5.65 \\
\hline & Lpbu FAM 21835 & 125.3 & 3.96 & 11.9 & 9.8 & 6.2 & 5.58 \\
\hline & Lbu FAM 22050 & 133.8 & 2.60 & 7.7 & 9.5 & 6.0 & 5.56 \\
\hline \multirow[t]{2}{*}{ Cheese $\mathrm{pH}(\mathrm{N}=8)$} & Standard $^{\mathrm{a}}$ & 88.0 & 0.29 & 7.4 & 10.9 & 6.5 & 5.70 \\
\hline & Acidic $^{b}$ & 178.1 & 3.12 & 7.7 & 8.2 & 5.6 & 5.40 \\
\hline \multirow[t]{3}{*}{ GLM ( $P$-value) } & Adjunct & $*$ & $* * *$ & $* * *$ & * & n.s. & $* * *$ \\
\hline & Cheese $\mathrm{pH}$ & $* * *$ & $* * *$ & n.s. & $* * *$ & $* * *$ & $* * *$ \\
\hline & Day/Run & n.s. & n.s. & n.s. & n.s. & n.s. & n.s. \\
\hline
\end{tabular}

Lpbu Lactobacillus parabuchneri, Lbu Lactobacillus buchneri, n.s. not significant

$* P \leq 0.05 ; * * * P \leq 0.001$

${ }^{\text {a }}$ Standard $=$ curd washed smear ripened Tilsit-type model cheeses

${ }^{\mathrm{b}}$ Acidic $=$ film ripened Tilsit-type model cheeses produced without curd washing

\subsection{Fermentation of arginine to ornithine}

As previously shown by Fröhlich-Wyder et al. (2013), all the investigated strains had strong ADI activity. Independently of the $\mathrm{pH}$ value, almost all the

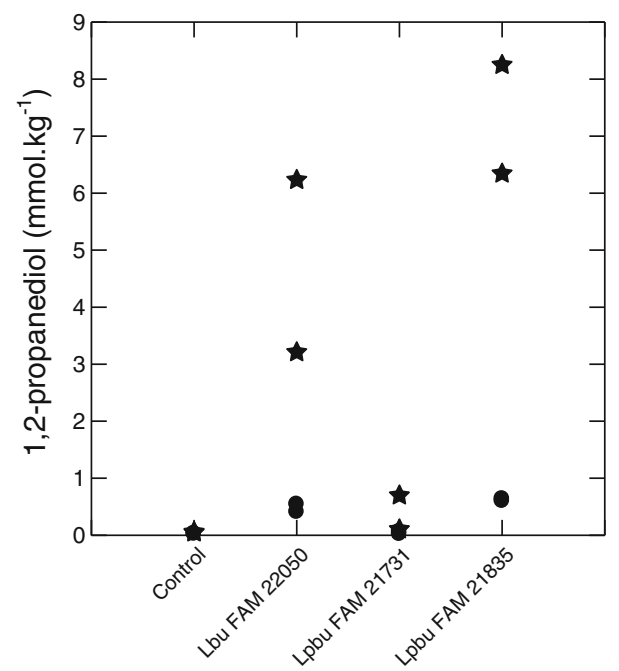

Fig. 1 Content of 1,2-propanediol in the 90-day aged Tilsit-type model standard cheeses (black circle) and acidic cheeses (black star). Both groups of cheeses included cheeses without adjuncts (control) and with adjuncts of Lactobacillus parabuchneri FAM 21731 (Lpbu FAM 21731), L. parabuchneri FAM 21835 (Lpbu FAM 21835) or L. buchneri FAM 22050 (Lbu FAM 22050) 


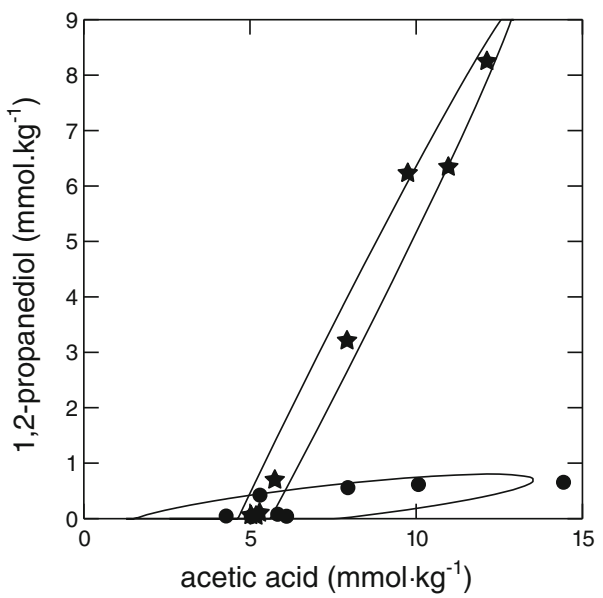

Fig. 2 Relationship between the content of 1,2-propanediol and acetic acid in 90-day aged Tilsit-type model standard cheeses (black circle) and acidic cheeses (black star). Both groups of cheeses included cheeses without adjuncts (control) and with adjuncts of Lactobacillus parabuchneri FAM 21731, L. parabuchneri FAM 21835 or L. buchneri FAM 22050

available arginine was metabolised to ornithine, an indicator of an active ADI pathway (Table 6). In addition, in the control cheeses, elevated concentrations of ornithine (4.01 mmol. $\mathrm{kg}^{-1}$, on average) were observed. This was probably due to the lactobacilli present in the starter culture using the same pathway.

Table 5 Sensory evaluation of the Tilsit-type model cheeses produced with various adjuncts after 90 days of ripening. No adjuncts were added to the control cheese. The score given was from one for the lowest to five for the highest intensity of the assessed attribute

\begin{tabular}{lllllllllll}
\hline \multirow{2}{*}{ Factor } & Level & bitter & sour & sweet & salty & $\begin{array}{l}\text { Flavour } \\
\text { quality }\end{array}$ & $\begin{array}{l}\text { Texture } \\
\text { elasticity }\end{array}$ & $\begin{array}{l}\text { Eye } \\
\text { quantity }\end{array}$ & $\begin{array}{l}\text { Eye } \\
\text { quality }\end{array}$ \\
\hline \multirow{2}{*}{ Adjunct (N=4) } & & Control & 1.75 & 2.93 & 1.89 & 2.36 & 3.29 & 3.25 & 2.79 & 2.64 \\
& Lpbu FAM 21731 & 2.36 & 3.00 & 1.50 & 2.43 & 1.79 & 3.25 & 3.60 & 2.64 \\
& Lpbu FAM 21835 & 1.89 & 3.00 & 2.00 & 2.39 & 3.11 & 3.32 & 2.97 & 2.64 \\
& Lbu FAM 22050 & 2.04 & 2.93 & 1.82 & 2.36 & 3.36 & 3.43 & 3.57 & 2.64 \\
Cheese pH (N=8) & Standard & 2.07 & 2.56 & 1.80 & 2.59 & 3.27 & 4.45 & 2.71 & 4.11 \\
& Acidic & & 1.95 & 3.38 & 1.80 & 2.18 & 2.50 & 2.18 & 3.77 & 1.18 \\
GLM $(P$-value) & Adjunct & $*$ & n.s. & $*$ & n.s. & $* * *$ & n.s. & $*$ & n.s. \\
& Cheese pH & n.s. & $* * *$ & n.s. & $* * *$ & $* * *$ & $* * *$ & $* * *$ & $* * *$ \\
& Day/Run & n.s. & $* *$ & n.s. & n.s. & $*$ & n.s. & n.s. & n.s. \\
\hline
\end{tabular}

Lpbu Lactobacillus parabuchneri, Lbu Lactobacillus buchneri, n.s. not significant $* P \leq 0.05 ; * * P \leq 0.01 ; * * * P \leq 0.001$

${ }^{\text {a }}$ Standard $=$ curd washed smear ripened Tilsit-type model cheeses

${ }^{\mathrm{b}}$ Acidic $=$ film ripened Tilsit-type model cheeses produced without curd washing 
The enzymes involved in the ADI pathway appear to be inherently acid

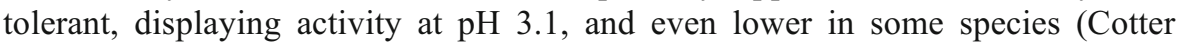
and Hill 2003). In acidic environments, arginine consumption leads to an increase in $\mathrm{pH}$ because ammonia is produced by the ADI pathway (Araque et al. 2013). In the present study, the low $\mathrm{pH}$ conditions of the acidic cheeses seemed to have only a slight influence on the formation of ornithine. However, there was one exception (Fig. 3): L. parabuchneri FAM 21835 produced significantly more ornithine in the acidic cheeses as compared to the standard cheeses $(P=0.046)$. During lactate fermentation under acid stress, it also produced considerably more 1,2-propanediol than the other two adjuncts (Fig. 1). The aforementioned may be due to L. parabuchneri FAM 21835 neutralising the cell environment only by the metabolism of lactate and arginine. In contrast, the two other adjuncts possess additionally amino acid decarboxylation activities, enabling them to respond to acid conditions by the formation of biogenic amines and by proton uptake (De Angelis and Gobbetti 2004; Molenaar et al. 1993). Linares et al. (2012) suggested that the formation of biogenic amines by the decarboxylation of amino acids might be a system for neutralisation of low extracellular $\mathrm{pH}$, thereby increasing survival under acidic stress conditions.

\subsection{Formation of GABA}

Lactobacillus buchneri FAM 22050 showed GAD activity during laboratory characterisation, showing that it has the ability to decarboxylase glutamic acid to GABA (Table 1). As expected, in the standard $\mathrm{pH}$ group, the cheeses with this adjunct

Table 6 Content of arginine (Arg), citrulline (Cit), ornithine (Orn), glutamic acid (Glu), $\gamma$-aminobutyric acid (GABA), histidine (His) and histamine (HIST) (mmol.kg-1) in Tilsit-type model cheeses produced with various adjuncts after 90 days of ripening. No adjuncts were added to the control cheese

\begin{tabular}{|c|c|c|c|c|c|c|c|c|}
\hline Factor & Level & Arg & Cit & Orn & Glu & GABA & His & HIST \\
\hline \multirow[t]{4}{*}{ Adjunct $(\mathrm{N}=4)$} & Control & 0.27 & 3.73 & 4.01 & 7.47 & 9.50 & 3.08 & 0.03 \\
\hline & Lpbu FAM 21731 & 0.05 & 0.10 & 7.67 & 6.92 & 10.17 & 0.21 & 3.28 \\
\hline & Lpbu FAM 21835 & 0.06 & 0.15 & 9.00 & 9.07 & 7.87 & 3.42 & 0.00 \\
\hline & Lbu FAM 22050 & 0.07 & 0.10 & 8.03 & 4.80 & 11.04 & 3.33 & 0.02 \\
\hline \multirow[t]{2}{*}{ Cheese $\mathrm{pH}(\mathrm{N}=8)$} & Standard $^{\mathrm{a}}$ & 0.12 & 1.02 & 6.74 & 11.78 & 4.62 & 3.18 & 0.91 \\
\hline & Acidic $^{b}$ & 0.11 & 1.02 & 7.61 & 2.36 & 14.67 & 1.85 & 0.76 \\
\hline \multirow[t]{3}{*}{ GLM ( $P$-value) } & Adjunct & $* * *$ & $* * *$ & $* * *$ & n.s. & n.s. & $* * *$ & $* * *$ \\
\hline & Cheese $\mathrm{pH}$ & n.s. & n.s. & $* *$ & $* * *$ & $* * *$ & $* *$ & n.s. \\
\hline & Day/Run & n.s. & n.s. & n.s. & n.s. & n.s. & n.s. & n.s. \\
\hline
\end{tabular}

Lpbu Lactobacillus parabuchneri, Lbu Lactobacillus buchneri, n.s. not significant

$* * P \leq 0.01 ; * * * P \leq 0.001$

${ }^{\text {a }}$ Standard $=$ curd washed smear ripened Tilsit-type model cheeses

${ }^{\mathrm{b}}$ Acidic $=$ film ripened Tilsit-type model cheeses produced without curd washing 


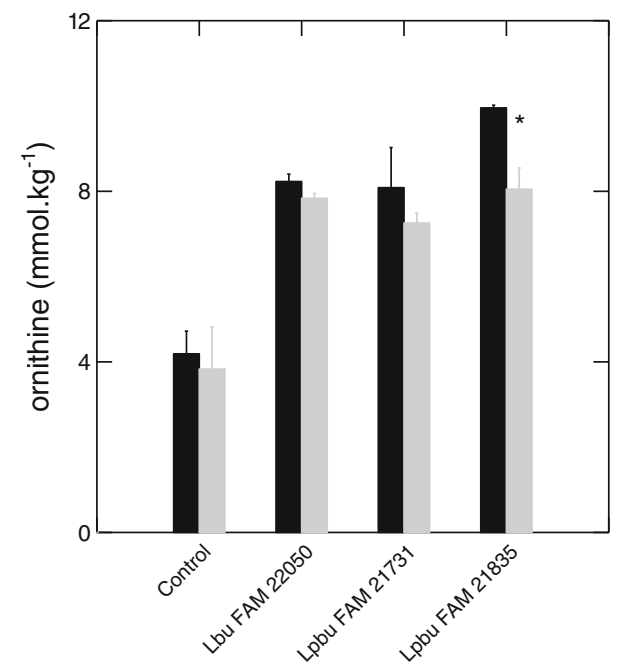

Fig. 3 Determination of ornithine in 90-day aged Tilsit-type model standard cheeses (grey bar) and acidic cheeses (black bar). Both groups of cheeses included cheeses without adjuncts (control) and with adjuncts of Lactobacillus parabuchneri FAM 21731 (Lpbu FAM 21731), L. parabuchneri FAM 21835 (Lpbu FAM 21835 ) or L. buchneri FAM 22050 (Lbu FAM 22050). The error bars indicate the standard error $(N=2)$. ${ }^{*} P \leq$ 0.05

contained more GABA than the cheeses with the other adjuncts and the control. In the acidic cheeses, the control and the cheeses made with the adjuncts had comparable amounts of GABA. The optimum $\mathrm{pH}$ for decarboxylases is around 5.0. As shown in Fig. 4, there was a very significant interaction $(P<0.001)$ between the strain-specific capability of GABA formation and the $\mathrm{pH}$ level of

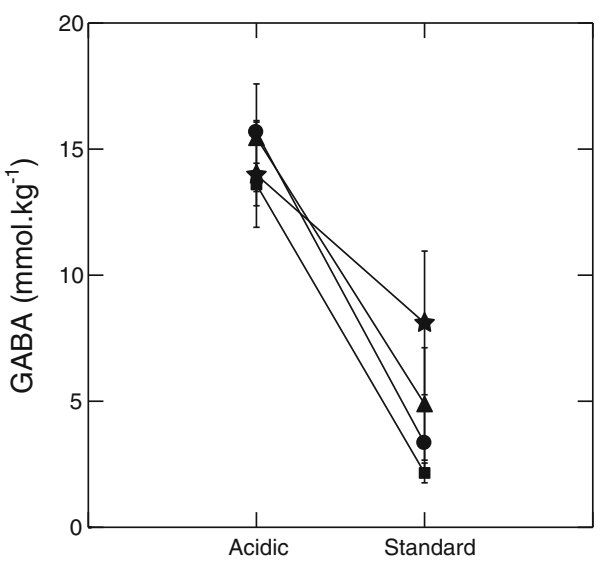

Fig. 4 Determination of $\gamma$-aminobutyric acid (GABA) in the standard and acidic Tilsit-type model cheeses. Both groups of cheeses included cheeses with adjuncts of Lactobacillus buchneri FAM 22050 (black star), L. parabuchneri FAM 21731 (black triangle), L. parabuchneri FAM 21835 (black square) and control cheeses without an adjunct (black circle). The error bars indicate the standard error $(N=2)$.

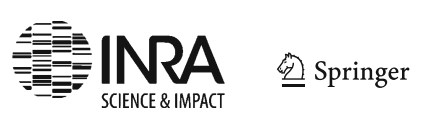


the cheeses, revealing that the starter culture also possessed GAD activity. A previous study demonstrated that the same starter culture produced considerable amounts of GABA under similar acidic conditions (Bisig et al. 2014). Various species of LAB possess GAD activity, as demonstrated by several studies (e.g. Dhakal et al. 2012). It seems that the GAD activity of the applied starter was even more sensitive than L. buchneri FAM 22050 to acidic stress. A possible explanation could be that L. buchneri FAM 22050 is able to ferment lactate and arginine, both of which are also involved in its $\mathrm{pH}$ homeostasis (Cotter and Hill 2003). In contrast, the LAB present in the starter culture fermented only arginine, to some extent, but not lactate. Thus, the decarboxylation of glutamic acid was probably the main type of metabolism used by the starter culture to achieve $\mathrm{pH}$ homeostasis, whereas L. buchneri FAM 22050 combined several metabolic activities to do so (De Angelis and Gobbetti 2004).

\subsection{Formation of histamine}

Lactobacillus parabuchneri FAM 21731 showed HDC activity in laboratory analyses (Table 1) and converted histidine in cheese to histamine (Table 6). The decarboxylation of histidine is considered to contribute to $\mathrm{pH}$ homeostasis and the control of acidic stress (Linares et al. 2012; Molenaar et al. 1993). Moreover, acidic pH conditions induce structural changes in HDC that are necessary for its activity (Coton et al. 1998; Linares et al. 2011); HDC is inactive at alkaline to neutral pH. As expected, only L. parabuchneri FAM 21731 produced histamine in the cheeses. Histamine formation tends to be higher in standard cheeses than in the acidic ones (Table 6). This finding can be explained by the different availability of histidine in the standard and acidic cheeses. In the standard cheeses, the $\mathrm{pH}$ throughout the whole ripening period was closer to the $\mathrm{pH}$ optimum of most bacterial proteinases and peptidases, the latter being responsible for the release of free amino acids (Upadhyay et al. 2004). As a result, more intensive proteolysis was observed in the standard cheeses than in the acidic cheeses. The latter is the most likely explanation for the higher soluble nitrogen and non-protein nitrogen and thus the histidine content in the standard cheeses (Table 4).

In the studies of Bisig et al. (2014) and Fröhlich-Wyder et al. (2013), L. parabuchneri FAM 21731 played an important role in $\mathrm{CO}_{2}$ production and in a strong burning taste detected in the cheeses. $\mathrm{CO}_{2}$ originates from the decarboxylation of histidine, and the burning taste is associated with the inflammation of mucosa in the mouth by histamine (Bachmann et al. 2011).

\subsection{Influence on $\mathrm{pH}$ in cheese}

As shown in the previous sections, the different $\mathrm{pH}$ values in the two groups of Tilsit-type model cheeses had a strong effect on the metabolism of the investigated L. buchneri and L. parabuchneri strains responding to acidic stress. Previous studies showed that these pathways-fermentation of lactate and of arginine, decarboxylation of amino acids - contributed to the neutralisation of the surrounding matrix and thus, to some extent, influenced the development of 
the $\mathrm{pH}$ during cheese ripening (Araque et al. 2013; Cotter and Hill 2003; De Angelis and Gobbetti 2004; Dhakal et al. 2012; Fröhlich-Wyder et al. 2013). In the present study, the increases in $\mathrm{pH}$ throughout the whole ripening time were dependent on the applied strains (Table 4 and Fig. 5). Compared to the control, the HDC-positive strain L. parabuchneri FAM 21731 had the most potent effect on $\mathrm{pH}$, both in the acidic and standard cheeses, and was able to raise the $\mathrm{pH}$ by about 0.2 units. Although histamine production was less pronounced in the acidic cheeses (see section 3.6) in the present study, the results confirm the important role of histamine production in the neutralisation of the surrounding cheese body. The other two strains, L. parabuchneri FAM 21835 and L. buchneri FAM 22050, also had a significant alkalising effect, with FAM 22050 being the less potent. An analysis of covariance showed that the increase in $\mathrm{pH}$ could be explained by the degradation of lactate and the production of histamine and ornithine $\left(R^{2}=0.966\right.$, with $\left.P<0.001\right)$.

\section{8 $\mathrm{CO}_{2}$ formation in the cheese}

As reported elsewhere, the ADI metabolism, degradation of lactate to 1,2-propanediol and decarboxylation of amino acids by L. buchneri and L. parabuchneri all contribute to the production of $\mathrm{CO}_{2}$ and thus influence eye formation and overall cheese quality (Fröhlich-Wyder et al. 2013; Bisig et al. 2014). In the present work, the lower $\mathrm{pH}$ value in the acidic cheeses promoted the degradation of lactate to 1,2-propanediol and of glutamic acid to GABA, both of which affected the production of $\mathrm{CO}_{2}$ and eye formation. The production of $\mathrm{CO}_{2}$ can be estimated by the quantity and types of metabolites generated in the abovementioned pathways. During the ADI metabolism, $\mathrm{CO}_{2}$ and ornithine are released in equimolar amounts (Manca de Nadra et al. 1986). Lactate degradation results in equimolar amounts of 1,2-propanediol, acetic acid and $\mathrm{CO}_{2}$ (Oude Elferink et al. 2001), and the decarboxylation of amino acids yields equimolar amounts of the corresponding amine and $\mathrm{CO}_{2}$ (e.g. Park and Oh 2006). The data presented in Fig. 6 reveal that the amount of $\mathrm{CO}_{2}$ produced in the acidic cheeses was twice as high as that produced in the standard cheeses.

In terms of cheese quality, the $\mathrm{pH}$ of the cheese plays an important role not only in the development of the texture and flavour during ripening but also in the solubility of $\mathrm{CO}_{2}$. Figure $7 \mathrm{a}$ of the cross-sections of the standard cheeses shows that they exhibited mostly round-shaped eyes. It also shows that the Tilsit-type model cheeses with the addition of an adjunct culture tended to have more eyes than the control cheeses (nos. 2 and 13). In contrast to the standard cheeses, the acidic cheeses exhibited mainly splits and cracks and no round-shaped eyes (Fig. 7b). The $\mathrm{pH}$ of a cheese has an important influence on the texture of the cheese body and the solubility of $\mathrm{CO}_{2}$ (Upadhyay et al. 2004; Jakobsen and Jensen 2009). A cheese with a low pH is associated with the formation of a brittle texture and reduced solubility of $\mathrm{CO}_{2}$ in the cheese body. Therefore, it is not surprising that the eye formation in the acidic cheeses was defective. These observations reflect the results of the sensorial evaluation of the attributes eye quantity and quality (Table 5).

The sensorial evaluation of the cheeses primarily revealed that L. parabuchneri FAM 21731 resulted in an unpleasant burning taste in the mouth (Bachmann et al. 2011). The burning taste was mirrored in the high 


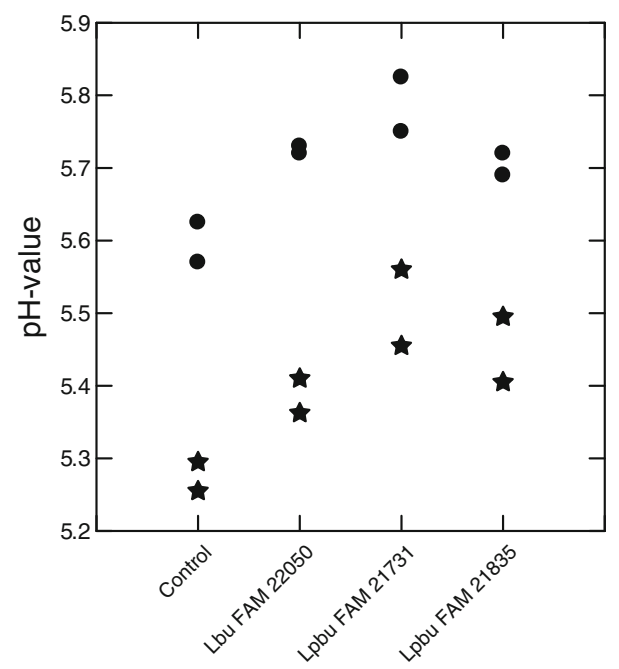

Fig. 5 Determination of the pH value in 90-day aged Tilsit-type model standard cheeses (black circle) and acidic cheeses (black star). Both groups of cheeses included cheeses without adjuncts (control) and with adjuncts of Lactobacillus parabuchneri FAM 21731 (Lpbu FAM 21731), L. parabuchneri FAM 21835 (Lpbu FAM 21835) or L. buchneri FAM 22050 (Lbu FAM 22050)

scores for the attribute 'bitter' as the closing discussion within the panel revealed. As expected, the acidic cheeses did not meet the quality expectations of the panellists: Compared to the standard cheeses, they were sour, less aromatic, less salty, had more flavour defects and were brittle in texture. Therefore, they were all downgraded (Table 5).

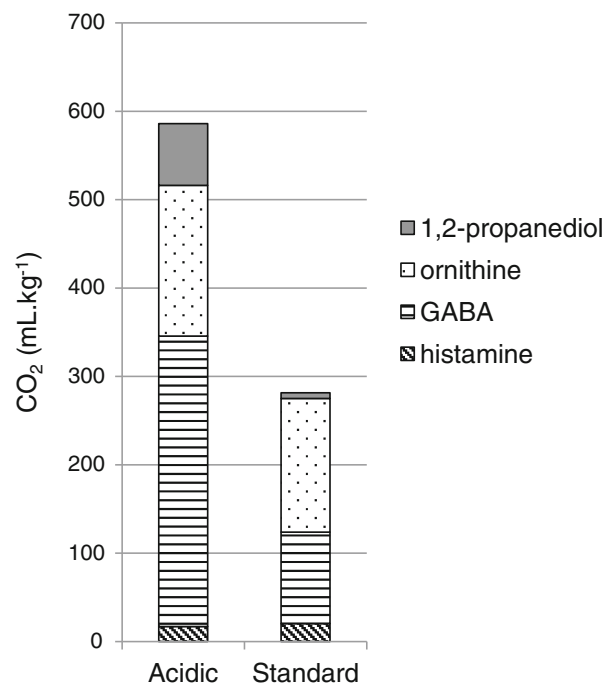

Fig. 6 Estimation of theoretically produced amounts of $\mathrm{CO}_{2}\left(\mathrm{~mL} \cdot \mathrm{kg}^{-1}\right.$ under atmospheric pressure at room temperature) in the 90-day aged Tilsit-type model standard and acidic cheeses $(N=8 \mathrm{each})$. The calculation of estimated $\mathrm{CO}_{2}$ was made on the basis of the following metabolites: 1,2-propanediol, ornithine, $\gamma$-aminobutyric acid (GABA) and histamine 

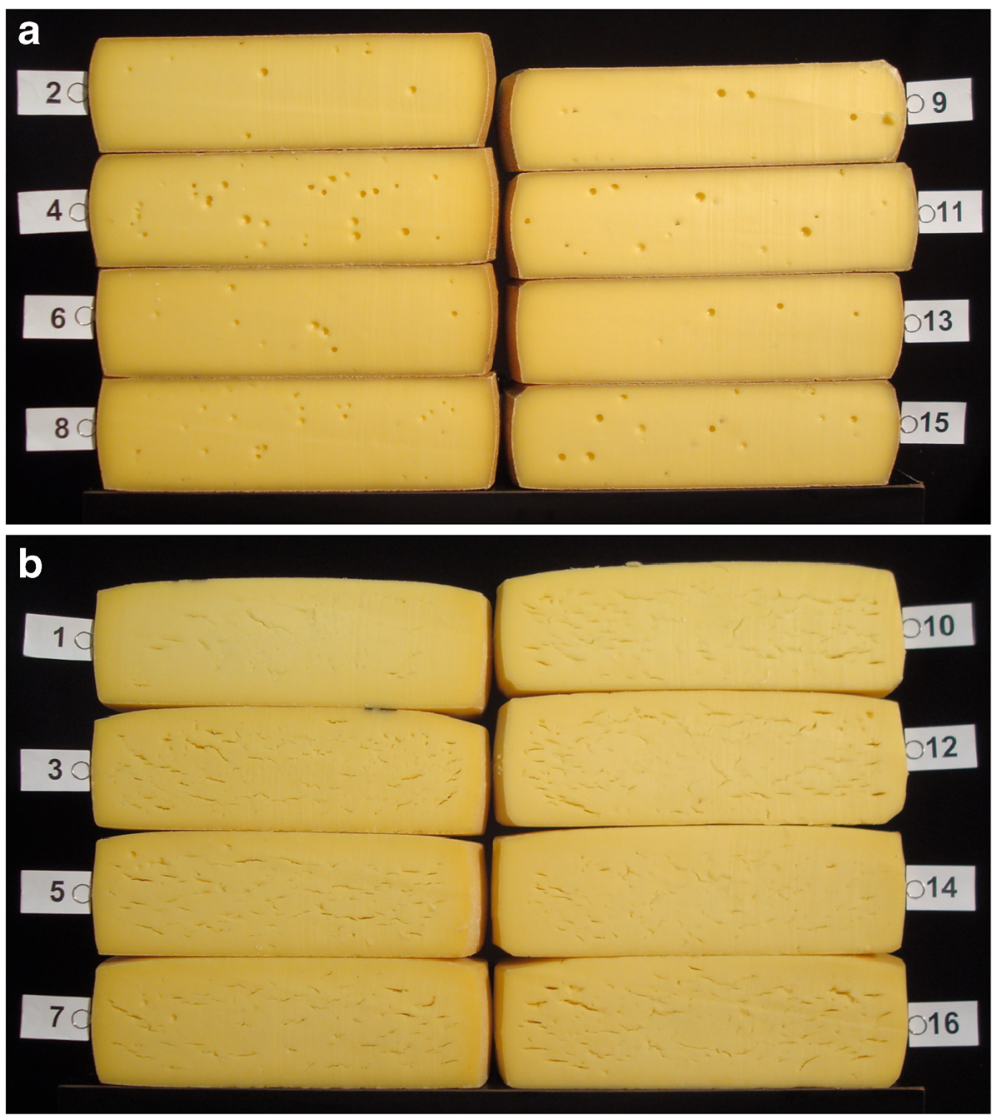

Fig. 7 Sectional view of the 90-day aged Tilsit-type model standard cheeses (a) and acidic cheeses (b). Both groups of cheeses included cheeses with adjuncts of Lactobacillus parabuchneri FAM 21731 (cheese nos. 3, 4, 15 and 16), L. parabuchneri FAM 21835 (cheese nos. 5, 6, 9 and 10) or L. buchneri FAM 22050 (cheese nos. $7,8,11$ and 12). The control cheeses (nos. 1,2,13 and 14) were made without an adjunct

\section{Conclusions}

The process of cheese making involves a number of steps, such as heating, acidification and brine salting. These steps cause stress to microorganisms, inhibit their growth and can even lead to their inactivation. The bacterial stress response enables bacteria to survive adverse and fluctuating conditions in their respective habitats. Lactic acid fermentation leads to a drastic drop in the $\mathrm{pH}$ value of cheese and induces acidic stress on most microorganisms involved in cheese ripening. Additionally, the fast conversion of available carbohydrates into organic acids results in carbohydrate starvation. The microorganisms present in the starter, adjunct and surface cultures, the growth of NSLAB and the actions of indigenous milk and clotting enzymes all influence the complex biochemical process of cheese ripening. The degradation of arginine by the ADI pathway, decarboxylation of histidine or glutamate into the corresponding biogenic amine and degradation of lactate into 1,2-propandiol by L. buchneri and L. parabuchneri are important metabolic pathways in the response to acidic stress. The growth of these NSLAB in cheese accelerates the increase in $\mathrm{pH}$ and promotes the 
production of $\mathrm{CO}_{2}$ during cheese ripening, thereby affecting the texture, openness and flavour of cheese. Recently, the growth of histamine-producing strains of L. parabuchneri has been associated with serious cheese defects, such as crack formation and a burning taste. However, only a few studies have investigated the metabolic activity of these NSLAB in cheese so far. In the present study, the metabolic stress response varied considerably among the three investigated strains. For example, L. parabuchneri FAM 21731, a histamine-positive strain, produced only small amounts of 1,2-propanediol under acidic conditions, whereas L. parabuchneri FAM 21835, a histamine-negative strain, produced the highest amounts of 1,2-propanediol. This example illustrates that strain-specific properties play an important role in the response to acidic stress. Despite the differences in the individual mechanisms used, the results clearly showed that acidic conditions favoured the degradation of lactate and arginine. An estimation of the amount of $\mathrm{CO}_{2}$ produced revealed that the ADI metabolism and the decarboxylation of glutamic acid were the most important sources of gas production. Although this study clearly demonstrated the importance of the cheese $\mathrm{pH}$ in the metabolic activity of strains of L. buchneri and L. parabuchneri during cheese ripening, further studies are needed to understand the role of these two species, which are frequently found in silage and therefore in milk, in the overall quality of cheese.

\section{References}

Araque I, Bordons A, Reguant C (2013) Effect of ethanol and low pH on citrulline and ornithine excretion and arc gene expression by strains of Lactobacillus brevis and Pediococcus pentosaceus. Food Microbiol 33: $107-113$

Bachmann HP, Fröhlich-Wyder MT, Jakob E, Roth E, Wechsler D (2011) In: Fuquay JW et al (eds) Encyclopedia of dairy sciences, volume 1, 2nd edn. San Diego, Academic Press

Bisig W, Guggisberg D, Irmler S, Jakob E, Wechsler D, Fröhlich-Wyder MT (2014) Measurement of $\mathrm{CO}_{2}$ from metabolic activity of adjunct cultures during cheese ripening. In: The ninth cheese symposium 12th $\&$ 13th November 2014, Teagasc, Cork, Ireland

Cho YR, Chang JY, Chang HC (2007) Production of gamma-aminobutyric acid (GABA) by Lactobacillus buchneri isolated from Kimchi and its neuroprotective effect on neuronal cells. J Microbiol Biotechn 17: 104-109

Coton E, Rollan GC, Lonvaud-Funel A (1998) Histidine carboxylase of Leuconostoc oenos 9204: purification, kinetic properties, cloning and nucleotide sequence of the hdc gene. J Appl Microbiol 84:143-151

Coton M, Berthier F, Coton E (2008) Rapid identification of the three major species of dairy obligate heterofermenters Lactobacillus brevis, Lactobacillus fermentum and Lactobacillus parabuchneri by species-specific duplex PCR. FEMS Microbiol Lett 284:150-157

Cotter PD, Hill C (2003) Surviving the acid test: responses of gram-positive bacteria to low pH. Microbiol Mol Biol R 67:429-453

De Angelis M, Gobbetti M (2004) Environmental stress responses in Lactobacillus: a review. Proteomics 4: 106-122

de Man J, Rogosa M, Sharpe ME (1960) A medium for the cultivation of Lactobacilli. J Appl Microbiol 23: $130-135$

Dhakal R, Bajpai VK, Baek KH (2012) Production of GABA (gamma-aminobutyric acid) by microorganisms: a review. Braz J Microbiol 43:1230-1241

Fröhlich-Wyder MT, Guggisberg D, Badertscher R, Wechsler D, Wittwer A, Irmler S (2013) The effect of Lactobacillus buchneri and Lactobacillus parabuchneri on the eye formation of semi-hard cheese. Int Dairy J 33:120-128

Guggisberg D, Fröhlich-Wyder MT, Irmler S, Greco M, Wechsler D, Schuetz P (2013) Eye formation in semihard cheese: X-ray computed tomography as a non-invasive tool for assessing the influence of adjunct lactic acid bacteria. Dairy Sci Technol 93:135-149 
Hufnagel JC, Hofmann T (2008) Quantitative reconstruction of the nonvolatile sensometabolome of a red wine. J Agric Food Chem 56:9190-9199

Isolini D, Grand M, Glättli H (1990) Selektivmedien zum Nachweis von obligat und fakultativ heterofermentativen Laktobazillen [Selective medium for the detection of obligatory and facultative heterofermentative Lactobacilli]. Schweiz Milchwirtsch Forsch 19:57-59

Jakobsen M, Jensen PN (2009) Assessment of carbon dioxide solubility coefficients for semihard cheeses: the effect of temperature and fat content. Eur Food Res Technol 229:287-294

Linares DM, Martin MC, Ladero V, Alvarez MA, Fernandez M (2011) Biogenic amines in dairy products. Crit Rev Food Sci 51:691-703

Linares DM, del Rio B, Ladero V, Martinez N, Fernandez M, Martin MC, Alvarez MA (2012) Factors influencing biogenic amines accumulation in dairy products. Front Microbiol 3, Article 180

Manca de Nadra MC, Nadra Chaud CA, de Ruiz P, Holgado AA, Oliver G (1986) Synthesis of the arginine dihydrolase pathway enzymes in Lactobacillus buchneri. Curr Microbiol 13:261-264

Manca de Nadra MC, Pesce de Ruiz Holgado AA, Oliver G (1988) Arginine dihydrolase pathway in Lactobacillus buchneri-a review. Biochimie 70:367-374

McSweeney PLH (2011) In: Fuquay JW (ed) Encyclopedia of dairy sciences, 2nd edn. San Diego, Academic Press

Molenaar D, Bosscher JS, Tenbrink B, Driessen AJM, Konings WN (1993) Generation of a proton motive force by histidine decarboxylation and electrogenic histidine histamine antiport in Lactobacillus buchneri. J Bacteriol 175:2864-2870

Oude Elferink SJ, Krooneman J, Gottschal JC, Spoelstra SF, Faber F, Driehuis F (2001) Anaerobic conversion of lactic acid to acetic acid and 1,2-propanediol by Lactobacillus buchneri. Appl Environ Microbiol 67: $125-132$

Park KB, Oh SH (2006) Isolation and characterization of Lactobacillus buchneri strains with high gammaaminobutyric acid producing capacity from naturally aged cheese. Food Sci Biotechnol 15:86-90

Skeie S, Kieronczyk A, Eidet S, Reitan M, Olsen K, Ostlie H (2008) Interaction between starter bacteria and adjunct Lactobacillus plantarum INF 15D on the degradation of citrate, asparagine and aspartate in a washed-curd cheese. Int Dairy J 18:169-177

Sumner SS, Speckhard MW, Somers EB, Taylor SL (1985) Isolation of histamine-producing Lactobacillus buchneri from Swiss cheese implicated in a food poisoning outbreak. Appl Environ Microbiol 50:10941096

Upadhyay VK, McSweeney PLH, Magboul AAA, Fox PF (2004) In: Fox PF et al (eds) Chemistry, physics and microbiology, volume 1, 3rd edn. Elsevier Academic Press, London

Yvon M, Gitton C, Chambellon E, Bergot G, Monnet V (2011) The initial efficiency of the proteolytic system of Lactococcus lactis strains determines their responses to a cheese environment. Int Dairy J 21:335-345 